\title{
Hepatocyte growth factor exerts beneficial effects on mice with type II diabetes-induced chronic renal failure via the $\mathrm{NF}-\kappa \mathrm{B}$ pathway
}

\author{
GUIMING CHENG, XUN TANG and JUN ZHANG
}

Department of Nephrology, Zhujiang Hospital, Southern Medical University, Guangzhou, Guangdong 510282, P.R. China

Received September 22, 2016; Accepted November 13, 2017

DOI: $10.3892 / \mathrm{mmr} .2018 .9297$

\begin{abstract}
Type II diabetes is associated with a low quality of life and inflammation, and is often accompanied by varying degrees of chronic renal failure. Chronic renal failure is considered one of the most important factors that aggravates diabetes and contributes to renal insufficiency in patients with diabetes though cellular fibrosis. It has previously been reported that hepatocyte growth factor (HGF) serves extensive biological roles, and is a multifunctional antifibrotic factor that is involved in kidney development, acute injury and regeneration. The present study aimed to investigate whether HGF exerts beneficial effects on type II diabetes-induced chronic renal failure in a mouse model. Plasma concentration levels of HGF, tumor necrosis factor (TNF)- $\alpha$, monocyte chemoattractant protein (MCP)-1, interleukin (IL)-1 and IL-6 were analyzed prior to and following treatment with HGF. Blood urea nitrogen, plasma creatinine concentrations, and electrolyte, total serum protein, parathyroid hormone and C-reactive protein levels were analyzed by ELISA. The mechanism underlying the effects of the HGF-mediated signaling pathway was also investigated in mice with type II diabetes-induced chronic renal failure. Histological analysis was used to determine the therapeutic effects of HGF on mice with type II diabetes-induced chronic renal failure. The results indicated that HGF exhibited lower plasma concentrations in mice with type II diabetes-induced chronic renal failure compared with in healthy mice. In addition, treatment with HGF relieved chronic renal failure via inhibition of inflammation. The results indicated that TNF- $\alpha$, MCP-1 and IL-1 serum concentration levels were downregulated following treatment with HGF. Conversely, IL-6 and vascular endothelial growth factor concentration was increased in the HGF-treated mice compared with in the control mice. The results also demonstrated that HGF treatment downregulated
\end{abstract}

Correspondence to: Professor Jun Zhang, Department of Nephrology, Zhujiang Hospital, Southern Medical University, 253 Gongye Avenue Middle, Guangzhou, Guangdong 510282, P.R. China

Email: zhangjun521mdi@163.com

Key words: hepatocyte growth factor, chronic renal failure, type II diabetes, inflammation, nuclear factor- $\kappa \mathrm{B}$ the expression of nuclear factor $(\mathrm{NF})-\kappa \mathrm{B}$ molecules, and target molecules $\mathrm{C}-\mathrm{C}$ motif chemokine ligand $(\mathrm{Ccl}) 2, \mathrm{Ccl} 5$, intercellular adhesion molecule 1 and TNF- $\alpha$. The present study demonstrated that HGF markedly improved renal failure induced by type II diabetes in a mouse model; histological analyses revealed that renal cell injury was improved following treatment with HGF. In conclusion, these results suggested that HGF may exert beneficial effects on type II diabetes-induced chronic renal failure via regulation of the $N F-\kappa B$ signaling pathway.

\section{Introduction}

Chronic renal failure is a syndrome associated with serious metabolic disorders and refers to damage caused by various types of chronic kidney disease (1). Inflammation is one of the most common characteristics of patients with type II diabetes (2), and is associated with dysfunctional urinary albumin excretion, endothelial function and cellular metabolism (3). In addition, hypertension is often present in patients with type II diabetes, and the onset of hypertension is a frequent focus of clinical investigations (4-6). A previous study reported that inhibition of the renin-angiotensin system was able to markedly decrease blood pressure by reducing vascular inflammation (7). However, long-term treatment with antihypertensive drugs may lead to a decline of renal function and may even cause chronic renal failure in patients with type II diabetes (8).

The main pathogeneses associated with chronic renal failure include glomerulonephritis, interstitial nephritis, high blood pressure, diabetes and nephritis (9). At present, the prevalence of diabetes-associated chronic renal failure is increasing, which may be due to the marked rapid increase in patients with diabetes worldwide $(10,11)$. A previous study noted that patients with diabetes and end-stage renal failure exhibited prolonged tissue healing of critical limb ischemia (12). In addition, chronic renal failure demands specific, continuous and varied care, which may present burden for family caregivers (13). Therefore, it is vital to investigate the association between chronic renal failure and type II diabetes in order to explore novel strategies for the diagnosis and treatment of patients with chronic renal failure.

Hepatocyte growth factor (HGF) is produced by mesenchymal cells during organ injury (14). HGF exerts 
extensive biological activities and serves as a multifunctional antifibrotic factor that has a critical role in kidney development, acute injury and regeneration. HGF is activated by proteolytic cleavage at the site of injury, thus resulting in generation of the biological HGF protein (15). A previous study reported that serum levels of HGF were correlated with quality of life in patients undergoing hemodialysis (16). Furthermore, biologically active HGF is able to suppress fibrosis, and a molecular basis for HGF-mediated regression of renal fibrosis has previously been elaborated on $(17,18)$. Therefore, HGF may be regarded as a local acute phase protein associated with chronic renal failure.

The present study aimed to investigate whether the expression and function of HGF were decreased and associated with inflammation in mice with type II diabetes-induced chronic renal failure. The results demonstrated that treatment with HGF markedly relieved chronic renal failure by decreasing the inflammatory response. Notably, the results revealed that HGF may improve chronic renal failure via the nuclear factor $(\mathrm{NF})-\kappa \mathrm{B}$ signaling pathway. These preclinical data may provide important information for doctors and clinicians in the treatment of patients with type II diabetes-induced chronic renal failure.

\section{Materials and methods}

Ethics statement. The present study was carried out in strict accordance with the recommendations in the Guide for the Care and Use of Laboratory Animals of Southern Medical University (Guangzhou, China). The study was approved by the ethics committee of Zhujiang Hospital, Southern Medical University. All surgical procedures and methods of euthanasia were conducted to minimize suffering.

Type II diabetes-induced chronic renal failure mouse model. HLA-A 2 mice with type II diabetes-induced renal failure (age, 16-18 weeks; $n=120$ ) were purchased from The Jackson Laboratory (Bar Harbor, ME, USA). All mice were feed under pathogen-free conditions and were given free access to food and water, and housed in a temperature-controlled facility at $23 \pm 1^{\circ} \mathrm{C}$ and relative humidity of $50 \pm 5 \%$ with a 12 -h light/dark cycle. The mice were divided into three groups ( $n=30 /$ group), which received treatment with HGF $(10 \mathrm{mg} / \mathrm{kg})$, aldosterone (positive control; 10 mg/kg, Sigma-Aldrich; Merck KGaA, Darmstadt, Germany) or PBS (10 $\mathrm{mg} / \mathrm{kg})$ once a day for 30 days with healthy mice $(n=30)$ as a control. Following 30-day treatment, the entire right kidney was removed, following a right flank incision under IV sodium pentobarbital (35 mg/kg) anesthesia, for subsequent analysis. The mice were sacrificed by cervical dislocation.

Renal cell analysis. Renal cells were isolated from experimental mice as described previously (19) with type II diabetes-induced chronic renal failure following treatment with HGF $(10 \mathrm{mg} / \mathrm{kg})$, aldosterone $(10 \mathrm{mg} / \mathrm{kg})$ or PBS. Serum was collected from $10 \mathrm{ml}$ blood using centrifugation at $6,000 \mathrm{x} \mathrm{g}$ for $10 \mathrm{~min}$ at $4^{\circ} \mathrm{C}$. Serum and urine samples were collected to analyze inflammatory factors and biochemical indexes. Renal cells also underwent immunohistochemical staining and western blotting.
Analysis of blood lipid levels. Serum samples were obtained from blood using centrifugation at 4,000 x $\mathrm{g}$ for $10 \mathrm{~min}$ at $4^{\circ} \mathrm{C}$. Concentration of TC, TG, HDL-C, LDL-C and VLDL-C were measured using the Roche Cobas 6000 analytical system according to the manufacturer's protocols (20).

ELISA. A total of $1 \mathrm{ml}$ blood was drawn from each mouse and centrifuged at $4,000 \mathrm{xg}$ for $15 \mathrm{~min}$ at $4^{\circ} \mathrm{C}$. To determine protein concentration, interleukin (IL)-1 (MLB00C; Bio-Rad Laboratories, Inc., Hercules, CA, USA), IL-8 (YJ1012360; Shanghai YiJi Industrial Co., Ltd.), IL-10 (DY417), HGF (MHG00; both Bio-Rad Laboratories, Inc.), monocyte chemoattractant protein (MCP)-1 (DCP00; Bio-Rad) and IL-6 (M6000B; Bio-Rad Laboratories, Inc.), blood urea nitrogen (0-012300; Shanghai Jianglai Biotechnology Co., Ltd.), plasma creatinine concentrations (KGE005; Bio-Rad Laboratories, Inc.), total serum protein (KA3946; Shanghai YaoYun Biotechnology Co. Ltd.), parathyroid hormone (6031) and C-reactive protein (MCRP00; both Bio-Rad Laboratories, Inc.) ELISA kits were used to determine serum concentration levels. The kits were used according to the manufacturer's protocols. The final results were recorded at $450 \mathrm{~nm}$ using an ELISA plate reader.

Reverse transcription-quantitative polymerase chain reaction $(R T-q P C R)$. Total RNA was extracted from renal cells prior to (healthy mice) or following treatment with HGF $(10 \mathrm{mg} / \mathrm{kg})$, aldosterone $(10 \mathrm{mg} / \mathrm{kg})$ or the same dose of PBS using RNAeasy Mini kit (Qiagen, Inc., Valencia, CA, USA). Subsequently, $1 \mu \mathrm{g}$ total RNA was transcribed into cDNA using a RT kit (Qiagen, Inc.) according to manufacturer's protocol and quality was confirmed by electrophoresis. cDNA (10 ng) was then subjected to qPCR (Bio-Rad Laboratories, Inc., Hercules, CA, USA) using the SYBR-Green Master Mix system. All forward and reverse primers were synthesized by Invitrogen (Thermo Fisher Scientific, Inc., Waltham, MA, USA) and are detailed in Table I. Thermocycling conditions were as follows: Pre-denaturation at $95^{\circ} \mathrm{C}$ for $120 \mathrm{sec}$, denaturation at $95^{\circ} \mathrm{C}$ for $30 \mathrm{sec}$ and annealing at $57^{\circ} \mathrm{C}$ for $10 \mathrm{sec}$ for 45 cycles. Relative mRNA expression levels were determined according to the $2^{-\Delta \Delta \mathrm{Cq}}$ method (21). The results are expressed as $n$-fold compared with the control ( $\beta$-actin).

Western blot analysis. Renal cells from experimental mice were homogenized in lysis buffer containing protease-inhibitor (Sigma-Aldrich; Merck KGaA) and were centrifuged at $6,000 \mathrm{x} \mathrm{g}$ at $4^{\circ} \mathrm{C}$ for $10 \mathrm{~min}$. The supernatant was then used to analyze protein expression. To detect proteins of interest, Protein concentration was measured by a BCA protein assay kit (Thermo Fisher Scientific, Inc.). Protein samples (20 $\mu \mathrm{g} /$ lane) were resolved by $15 \%$ SDS-PAGE and then transferred onto polyvinylidene fluoride membranes (Merck $\mathrm{KGaA}$ ) according to the manufacturer's protocol. For western blotting, primary antibodies: HGF (ab83760; 1:2,000), IKK- $\alpha$ (ab32041; 1:2,000), IKK- $\beta$ (ab7547; 1:2,000), NF- $\mathrm{KB}$ inhibitor $\alpha(\mathrm{I} \kappa \mathrm{B} \alpha ; \mathrm{ab} 133478 ; 1: 2,000)$ and $\beta$-actin (ab8827; $1: 2,000$; all from Abcam) were added to the polyvinylidene fluoride membranes following blocking with $5 \%$ skimmed milk for $1 \mathrm{~h}$ at $37^{\circ} \mathrm{C}$. Subsequently, membranes were incubated with horseradish peroxidase-labeled secondary goat anti-rabbit 
Table I. Sequences of primers used in the present study.

Sequence

\begin{tabular}{lll}
\cline { 2 - 3 } Gene & \multicolumn{1}{c}{ Reverse } & \multicolumn{1}{c}{ Forward } \\
\hline p53 & 5'-TTAAGCTTTTTGCGTTCGGGCTGGGAGC-3'-3' & 5'-ATGGTGGCATGAACCTGTGG-3' \\
Bid & 5'-CGACGAGGTGAAGACATCCT-3' & 3'-AGCAGAGATGGTGCATGAC-3' \\
Cc12 & 5'-CCCCAGTCACCTGCTGTTAT-3' & 5'-TGGAATCCTGAACCCACTTC-3' \\
Cc15 & 5'-TGTACAATACGCGCTACAGCTCCA-3' & 5'-ATGCACTCGTTCTGGTCTGCGTTA-3' \\
Icam-1 & 5'-GCCCTTGCCTCTGAGTAGTG-3' & 5'-CCAACCAAATGAAGCCAAG-3' \\
TNF $\alpha$ & 5'-ATGTTGTAGCAAACCCTCAA-3' & 5'-AGGACCTGGGAGTAGATGA-3' \\
$\beta$-actin & 5'-CCTTCCTGGGCATGGAGTCCT-3' & 5'-GGAGCAATGATCTTGATCTTC-3'
\end{tabular}

Bid, BH3 interacting-domain death agonist; Ccl, C-C motif chemokine ligand; Icam-1, intercellular adhesion molecule 1; TNF, tumor necrosis factor.

antibodies (ab150077; 1:2,000; Abcam) for $24 \mathrm{~h}$ at $4^{\circ} \mathrm{C}$. Blots were visualized using a chemiluminescence detection system (Pierce $^{\mathrm{TM}}$ Fast Western Blot kits, SuperSignal ${ }^{\mathrm{TM}}$ West Femto; Thermo Fisher Scientific, Inc.).

$N F-\kappa B$ activity. Renal cells $\left(1 \times 10^{6}\right.$ cells/well) were seeded in 6 -well plates for $12 \mathrm{~h}$ at $37^{\circ} \mathrm{C}$. NF- $\mathrm{BB}$-luc plasmids (Qiagen, Inc.) containing the response element were transfected into the renal cells, following replacement with MEM medium (Invitrogen; Thermo Fisher Scientific, Inc.) $12 \mathrm{~h}$ after transfection, the cells were then treated with various concentrations of apigenin. Cell lysate $(\mathrm{NF}-\kappa \mathrm{B})$ was collected on a 6-well white plate after $48 \mathrm{~h}$, and luciferase activity was detected using a luciferase reporter assay as described previously (22).

Immunohistochemicalstaining.Immunohistochemicalstaining was performed according to the avidin-biotin-peroxidase technique. Tissues were fixed with $10 \%$ formaldehyde for $2 \mathrm{~h}$ at $37^{\circ} \mathrm{C}$, then embedded in paraffin and sectioned at $4 \mu \mathrm{m}$. Epitope retrieval using Epitope Retrieval kit (cat. no. GTX30934; GeneTex, Inc., Irvine, CA, USA) was performed for further analysis. The paraffin-embedded sections were incubated with hydrogen peroxide (3\%) for 10-15 min at $37^{\circ} \mathrm{C}$, and were then blocked with regular blocking solution (5\% skimmed milk) for $10-15 \mathrm{~min}$ at $37^{\circ} \mathrm{C}$. Finally, the sections were incubated with anti-HGF (ab83760; 1:1,000), anti-CD3 (ab16669; 1:1,000), anti-kidney injury molecule (KM)-1 (ab47634; 1:1,000), anti-IL-18 (ab52914; 1:1,000), anti-cluster of differentiation (CD)86 (ab119857; 1:1,000; all from Abcam) at $4^{\circ} \mathrm{C}$ for $12 \mathrm{~h}$. All sections were washed three times with PBS at room temperature and were incubated with secondary antibodies horseradish peroxidase-conjugated anti-rabbit IgG secondary antibody (cat. no. 1721019; 1:5,000; Bio-Rad Laboratories, Inc.) for $1 \mathrm{~h}$ at $37^{\circ} \mathrm{C}$. For hematoxylin and eosin (H\&E) assay, tissue sections $(4 \mu \mathrm{m})$ were stained with $\mathrm{H} \& \mathrm{E}$ for $2 \mathrm{~h}$ at $37^{\circ} \mathrm{C}$. Then 6 random fields of view were observed under a fluorescent microscope (Olympus Corporation, Tokyo, Japan) at magnification, $\mathrm{x} 40$.

TUNEL assay. For analysis the apoptosis of renal cells in experimental mice after treatment with HGF, aldosterone or PBS, the terminal deoxynucleotidyl transferase
(TdT)-mediated dUTP nick end labeling (TUNEL) assay (Biotool) were used to detect TUNEL-positive cells. The procedures were performed by previous study (23). Finally, hippocampal neuron cells images were captured with a ZEISS LSM 510 confocal microscope at $488 \mathrm{~nm}$.

Statistical analysis. All data are presented as the mean \pm standard error of the mean of triplicate experiments. Comparisons between multiple groups were made by one-way analysis of variance followed by Dunnett's t test. $\mathrm{P}<0.05$ was considered to indicate a statistically significant difference.

\section{Results}

HGF expression, blood glucose, blood lipid levels and body weight in mice with chronic renal failure. In order to investigate the role of HGF in chronic renal failure, the present study analyzed the expression levels of HGF in renal cells from mice with chronic renal failure, and compared them with those in healthy mice. As shown in Fig. 1A, the expression levels of HGF were downregulated compared with the healthy mice. However, treatment with HGF upregulated HGF expression, as determined by western blotting. Furthermore, protein expression of HGF was decreased in chronic renal failure mice compared with healthy mice (Fig. 1B). Blood lipid levels were improved in mice with type II diabetes-induced chronic renal failure treated with HGF compared with in those treated with PBS (Fig. 1C). The present study also aimed to determine the therapeutic effects of HGF on body weight in a mouse model of type II diabetes-induced chronic renal failure. The results indicated that HGF markedly inhibited body weight compared with in the aldosterone-treated and control mice on day 30 (Fig. 1D). Collectively, these data suggested that HGF was downregulated in a mouse model of type II diabetes-induced chronic renal failure, whereas restoration of HGF exerted beneficial effects on blood lipid levels and body weight in mice with type II diabetes-induced chronic renal failure.

Effects of HGF on inflammatory factor expression in renal cells from experimental mice. The present study further analyzed the effects of HGF on inflammatory factor expression in renal cells from experimental mice. As presented in Fig. 2A, the results 
A

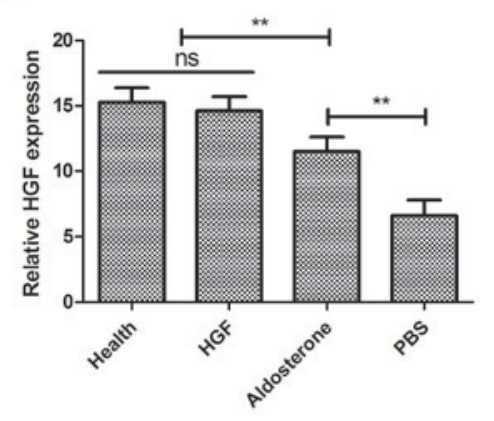

C

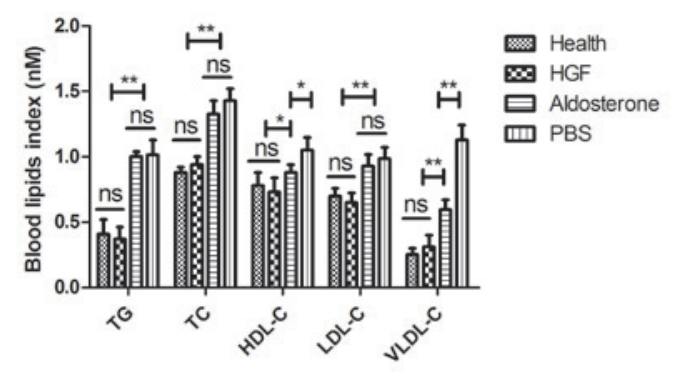

B

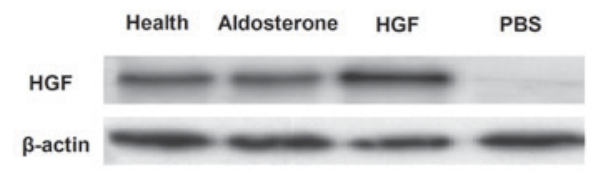

D

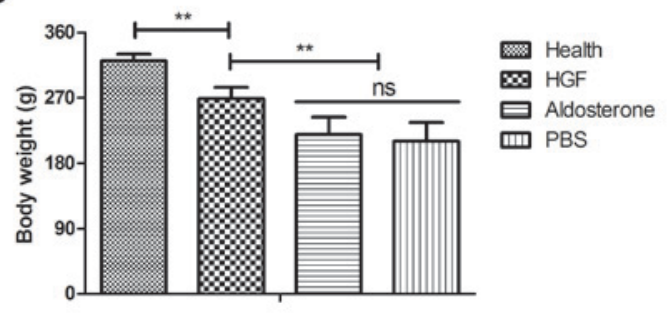

Figure 1. HGF expression and its effects on body function. (A) Detection of HGF mRNA expression in mice with type II diabetes-induced chronic renal failure. (B) Western blot analysis of HGF expression levels in mice with type II diabetes-induced chronic renal failure. (C) Evaluation of blood lipid levels in mice treated with HGF. (D) Body weight alterations in a mouse model of type II diabetes-induced chronic renal failure. Data are presented as the mean \pm standard error of the mean. ${ }^{*} \mathrm{P}<0.05,{ }^{* *} \mathrm{P}<0.01$. HDL-C, high-density lipoprotein cholesterol; HGF, hepatocyte growth factor; LDL-C, low-density lipoprotein cholesterol; TC, total cholesterol; TG, triglycerides; VLDL-C, very low-density lipoprotein cholesterol.

indicated that TNF- $\alpha$ plasma concentration levels were decreased following treatment with HGF compared with aldosterone. In addition, MCP-1 levels were downregulated in HGF-treated mice (Fig. 2B). IL-1 concentration levels were also decreased in mice with chronic renal failure following HGF treatment (Fig. 2C). Notably, HGF expression was recovered to normal levels following HGF treatment (Fig. 2D). Furthermore, the concentration levels of IL-6 and VEGF were increased in renal cells from experimental mice following HGF treatment, which may contribute to improved functioning of renal cells (Fig. 2E and F). These results suggested that treatment with HGF was beneficial for the treatment of mice with chronic renal failure.

Effects of $H G F$ on the $N F-\kappa B$ signaling pathway. A previous study demonstrated that $\mathrm{NF}-\kappa \mathrm{B}$ serves an essential regulatory role in inflammation, via its control of the expression of numerous genes involved in cellular activity (24). Therefore, the present study analyzed the association between HGF and the $N F-\kappa B$ signaling pathway in mice with type II diabetes-induced chronic renal failure. Treatment with HGF blocked the nuclear import of activated $N F-\kappa B(p 65)$ in renal cells from experimental mice (Fig. 3A). In addition, HGF treatment markedly suppressed activation of $\mathrm{NF}-\kappa \mathrm{B}$ in renal cells from mice on day 60 (Fig. 3B). The expression levels of $\mathrm{I} \kappa \mathrm{B}$ kinase $(\mathrm{IKK}) \alpha, \mathrm{IKK} \beta$ and $\mathrm{I} \kappa \mathrm{B}$ were downregulated in renal cells from mice treated with HGF (Fig. 3C). Furthermore, the present study indicated that HGF treatment decreased the expression levels of proinflammatory genes involved in the $\mathrm{NF}-\kappa \mathrm{B}$ signaling pathway, including $\mathrm{C}-\mathrm{C}$ motif chemokine ligand $(\mathrm{Ccl}) 2, \mathrm{Ccl} 5$, intercellular adhesion molecule 1 (Icam1) and TNF- $\alpha$, as determined by RT-qPCR (Fig. 3D). The present data also demonstrated that p53 and $\mathrm{BH} 3$ interacting-domain death agonist expression levels were decreased in renal cells following HGF treatment (Fig. 3E). Notably, the number of TUNEL-positive renal cells was markedly decreased following treatment with HGF (Fig. 3F). These results indicated that HGF may regulate the physiological functions of renal cells by controlling the $\mathrm{NF}-\kappa \mathrm{B}$ signaling pathway.

Effects of HGF on histopathological alterations of renal cells from mice with type II diabetes-induced chronic renal failure. To further determine the beneficial effects of HGF on the morphology and function of renal cells, histopathological alterations were analyzed by H\&E and immunohistochemical staining of renal cells. As shown in Fig. 4A, cellular morphology was improved following treatment with HGF, presenting a pebble-like shape that is typical renal cell morphology. In addition, KM-1 and IL-18 levels were downregulated following HGF treatment (Fig. 4B), and the number of immune cells was decreased in renal sections obtained from HGF-treated mice (Fig. 4C). Furthermore, reduced CD86 expression was detected in HGF-treated mice, whereas CD86 expression was much higher in the control group (Fig. 4D). These data indicated that the physiology of renal cells was improved in HGF-treated experimental mice.

Biochemical analysis of the therapeutic effects of HGF in mice with type II diabetes-induced chronic renal failure. Following detection of the histopathological alterations of renal cells from mice with type II diabetes-induced chronic renal failure, the plasma biochemical indexes of mice were determined following treatment with HGF. As shown in Fig. 5A, blood 
A

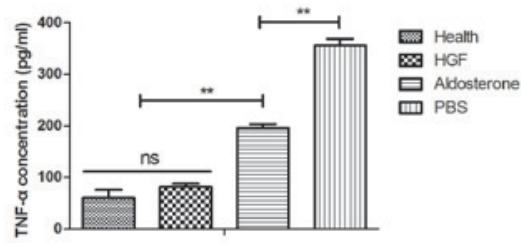

D
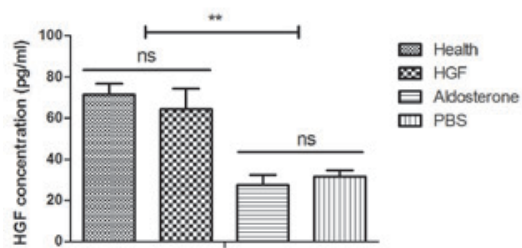

B

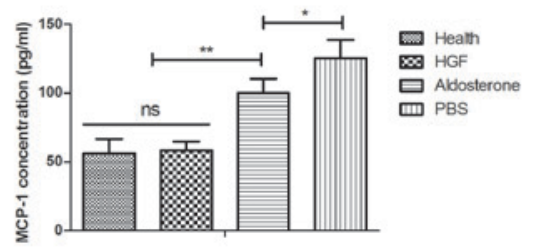

E

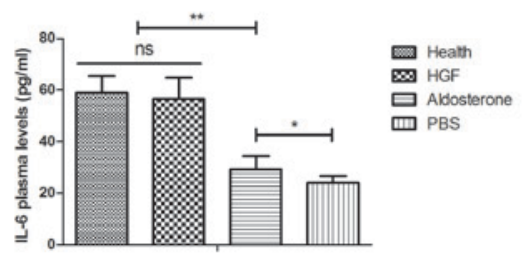

C

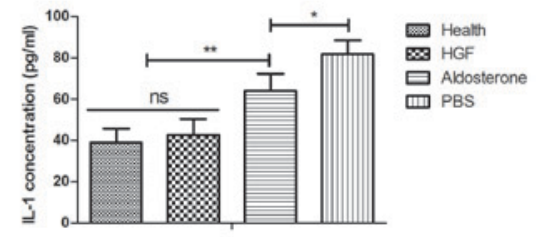

$\mathbf{F}$

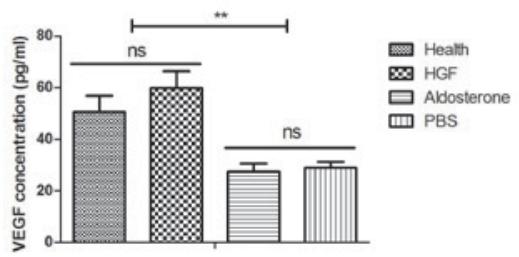

Figure 2. Analysis of inflammatory factor expression in renal cells from experimental mice following HGF treatment. (A) TNF- $\alpha$ (B) MCP-1 and (C) IL-1 plasma concentration levels in mice with chronic renal failure following treatment with the indicated agents. (D) Analysis of HGF concentration in mice following treatment with HGF $(10 \mathrm{mg} / \mathrm{kg}$ ), aldosterone $(10 \mathrm{mg} / \mathrm{kg})$ or the same dose of PBS. (E) IL-6 and (F) VEGF concentration levels in renal cells from experimental mice. Data are presented as the mean \pm standard error of the mean. ${ }^{*} \mathrm{P}<0.05,{ }^{* *} \mathrm{P}<0.01$. HGF, hepatocyte growth factor; IL, interleukin; MCP-1, monocyte chemoattractant protein 1 ; TNF- $\alpha$, tumor necrosis factor- $\alpha$; VEGF, vascular endothelial growth factor.

A

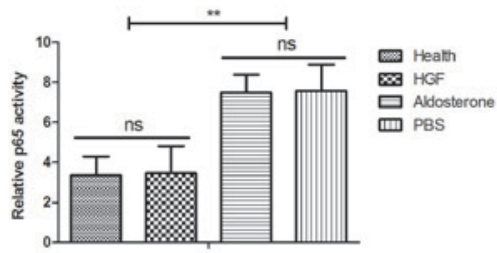

D

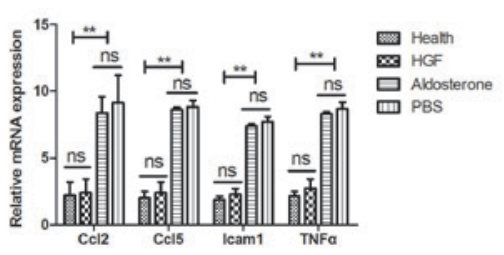

B

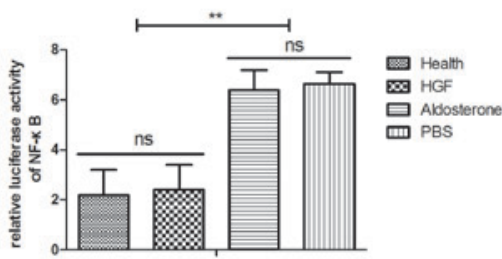

E

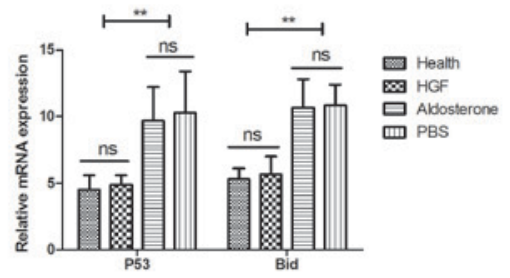

C

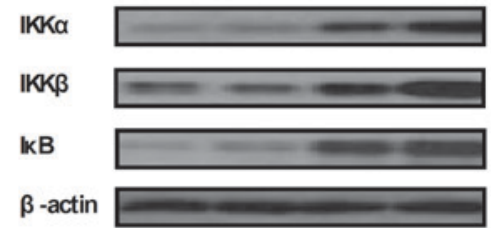

$\mathbf{F}$

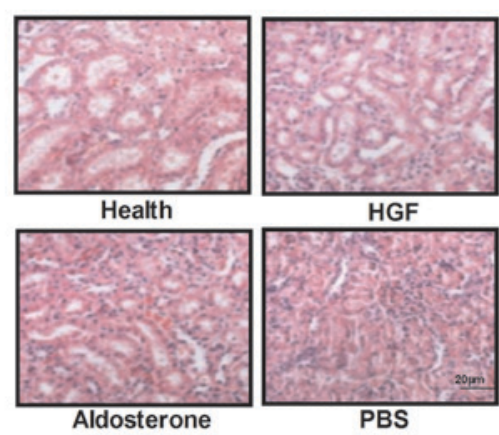

Figure 3. Mechanism underlying the HGF-mediated benefits against chronic renal failure. (A) Expression of p65 in renal cells from experimental mice following treatment with HGF, aldosterone and PBS. (B) Activation of NF- $\kappa$ B in renal cells from experimental mice. (C) IKK $\alpha$, IKK $\beta$ and I $\mathrm{B}$ expression levels in renal cells from mice treated with HGF, aldosterone and PBS. (D) Ccl2, Ccl5, Icam1 and TNF- $\alpha$ expression levels in renal cells following 30-day treatment. (E) Analysis of p53 and Bid expression levels in renal cells following treatment of mice with HGF, aldosterone and PBS. (F) Analysis of TUNEL-positive renal cells following treatment of mice with $\mathrm{HGF}$, aldosterone and $\mathrm{PBS}$. Data are presented as the mean \pm standard error of the mean. ${ }^{* *} \mathrm{P}<0.01$. Bid, $\mathrm{BH} 3$ interacting-domain death agonist; $\mathrm{Ccl}, \mathrm{C}-\mathrm{C}$ motif chemokine ligand; HGF, hepatocyte growth factor; Icam1, intercellular adhesion molecule 1; IKK, I $\mathrm{B}$ kinase; NF- $\kappa \mathrm{B}$, nuclear factor- $\kappa \mathrm{B}$; TNF- $\alpha$, tumor necrosis factor- $\alpha$.

urea nitrogen levels were decreased following HGF treatment. Creatinine plasma concentration levels also were downregulated in HGF-treated mice (Fig. 5B). In addition, electrolyte concentration was increased in renal cells obtained from the HGF group (Fig. 5C). Serum total protein content was also recovered to normal levels in HGF-treated mice (Fig. 5D). Furthermore, parathyroid hormone levels were upregulated and C-reactive protein (CRP) expression levels were downregulated in HGF-treated mice (Fig. 5E and F). Taken together, these data suggested that HGF not only improves renal cell histopathology, but also regulates the biochemical indexes of mice with type II diabetes-induced chronic renal failure.

\section{Discussion}

Previous studies have demonstrated that chronic renal failure may induce the formation of complex symptoms and reduce quality of life in patients $(25,26)$. In addition, patients with 
A

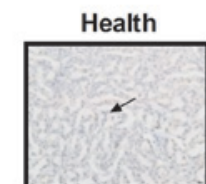

Aldosterone

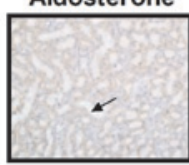

C
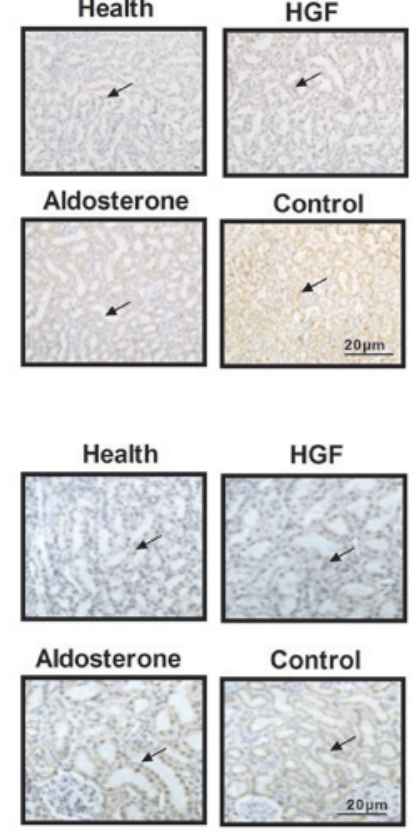

Control

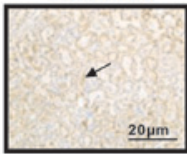

B

D

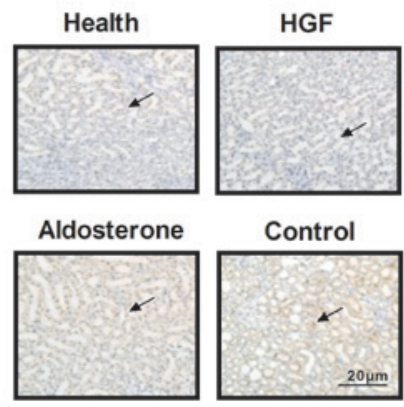

Figure 4. Histopathological alterations of renal cells from mice with chronic renal failure following treatment with HGF. (A) Analysis of cellular morphology, as determined by hematoxylin and eosin staining. Arrow indicates the arrangement of renal cells. (B) KM-1 and IL-18 expression levels in renal cells following HGF treatment. Arrow indicates KM-1- or IL-18-positive renal cells. (C) Analysis of immune cell accumulation in renal sections following HGF treatment. Arrow indicates CD3-positive renal cells. (D) Cluster of differentiation 86 expression levels in renal cells isolated from mice treated with HGF, aldosterone and PBS. Arrow indicates CD86-positive renal cells. HGF, hepatocyte growth factor; IL-18, interleukin-18; KM-1, kidney injury molecule-1.

A

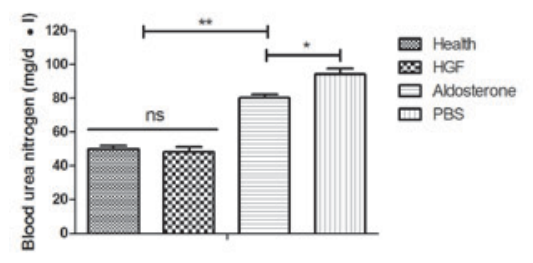

D

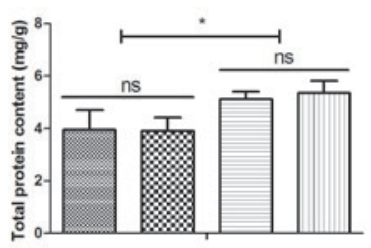

B

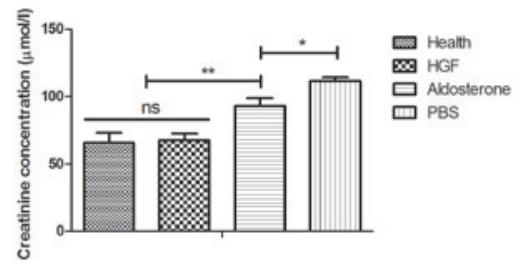

E

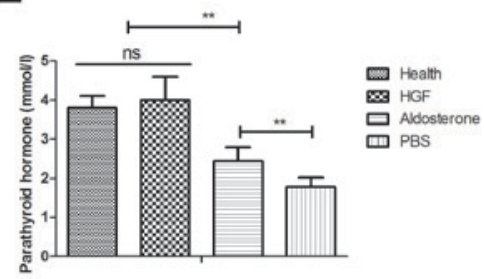

C

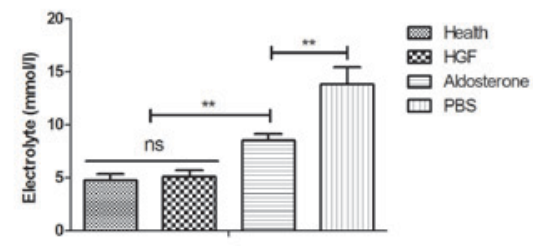

$\mathbf{F}$

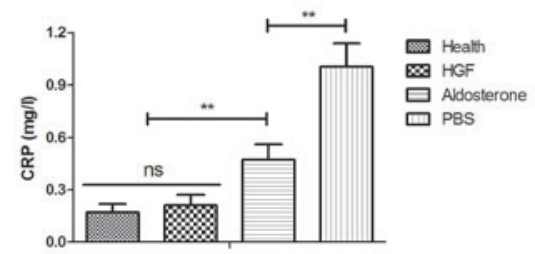

Figure 5. Biochemical analysis of the therapeutic effects of HGF in mice with chronic renal failure. (A) Alterations in blood urea nitrogen in mice following treatment with HGF, aldosterone and PBS. (B) Analysis of creatinine plasma concentration levels in HGF-treated mice. (C) Alterations in electrolyte turbulence following treatment of mice with HGF, aldosterone and PBS. (D) Serum total protein content was improved in HGF-treated mice. Analysis of (E) parathyroid hormone and $(\mathrm{F}) \mathrm{CRP}$ expression in renal cells isolated from experimental mice. Data are presented as the mean \pm standard error of the mean. ${ }^{*}<0.05$, ${ }^{* *} \mathrm{P}<0.01$. CRP, C-reactive protein; HGF, hepatocyte growth factor.

chronic renal failure frequently develop uremia, resulting in glomerular cell dysfunction and loss of the biological activity of kidney cells (27). Dialysis is the most effective treatment for multiple organ failure and deterioration of the quality of the life. In addition, the pathogenesis of chronic renal failure is genetic and multifactorial $(28,29)$. A previous study indicated that age has an important role in survival, limitation of physical activity and quality of life in patients with chronic renal failure (30). The present study investigated whether the expression and restoration of HGF affects inflammation, histopathological alterations and biochemical indexes in a mouse model of type II diabetes-induced chronic renal failure.

Inflammation is one of the most common characteristics of patients with type II diabetes (31). Temelkova-Kurktschiev et al (32) 
reported that subclinical inflammation was upregulated in patients with type II diabetes, thus indicating that inflammatory responses may be associated with the occurrence, degree and prognosis of diabetes. Varughese and Lip reported that inflammation was associated with hypertension and urinary albumin excretion in patients with type II diabetes (3). In addition, a previous study demonstrated that vascular inflammation serves an important role in drug-induced rapid and persistent reduction of urinary albumin excretion, endothelial function and inflammation in patients with hypertension and type II diabetes (2). Furthermore, Bitar et al reported that inflammation was associated with the degree of pathogenesis in aortic tissues from aged patients with type II diabetes via the phosphatidylinositol 3-kinase/protein kinase B-dependent signaling pathway (33). In the present study, the expression levels of inflammatory factors, including IL-6 IL-1, TNF- $\alpha$, MCP-1 and VEGF, were detected in mice with type II diabetes-induced chronic renal failure. The results indicated that these inflammatory factors were downregulated in response to HGF, and the NF- $\mathrm{B}$ signaling pathway was involved in HGF-mediated improvement of type II diabetes-induced chronic renal failure.

The present study indicated that treatment with HGF may regulate biochemical metabolism of renal cells via inactivation of the $\mathrm{NF}-\kappa \mathrm{B}$ signaling pathway. A previous study reported that $\mathrm{NF}-\kappa \mathrm{B}$-induced oxidative stress contributes to mitochondrial and cardiac dysfunction in type II diabetes (34). In addition, receptor activator of $\mathrm{NF}-\kappa \mathrm{B}$ ligand exerted beneficial effects for patients with chronic renal failure via inhibition of the NF- $\kappa \mathrm{B}$ signaling pathway (35). Biochemical indexes, including blood urea nitrogen, plasma creatinine concentration, electrolyte, serum protein, parathyroid hormone and CRP levels are crucial for normal kidney function. In the present study, these biochemical indexes were analyzed in mice with type II diabetes-induced chronic renal failure following treatment with HGF (36). The results revealed that HGF may be considered an efficient drug for the treatment of type II diabetes-induced chronic renal failure.

Although a previous study reported that inflammation is associated with hypertension in patients with type II diabetes, correlations between inflammatory factors and type II diabetes have not been clinically analyzed (37). To determine the association between HGF and serum inflammatory factors, the present preclinical study analyzed mice with type II diabetes-induced chronic renal failure. The results indicated that HGF treatment decreased the accumulation of immune cells in renal tissues in mice with type II diabetes-induced chronic renal failure.

In conclusion, based on these preclinical data, serum concentration levels of IL-1, TNF- $\alpha$ and MCP-1 may be increased in mice with type II diabetes-induced chronic renal failure. However, HGF treatment was revealed to decrease the expression of inflammatory factors in mice with type II diabetes-induced chronic renal failure. In addition, HGF was downregulated in mice with chronic renal failure, whereas restoration of HGF exerted beneficial effects on blood lipid levels and body weight in mice with type II diabetes-induced chronic renal failure. Furthermore, HGF regulated the physiological function and biochemical indexes of renal cells via regulation of the $N F-\kappa B$ signaling pathway. Overall, the present study researched the function of HGF in a mouse model of type II diabetes-induced chronic renal failure; however, the role of HGF in patients with renal failure induced by type II diabetes requires further study.

\section{Acknowledgements}

Not applicable.

\section{Funding}

No funding was received.

\section{Availability of data and materials}

The analyzed data sets generated during the study are available from the corresponding author on reasonable request.

\section{Authors' contributions}

GC and XT performed the experiments and JZ designed the experiments and analyzed the data. All the authors have read the manuscript and have approved this submission.

\section{Ethics approval and consent to participate}

The present study was carried out in strict accordance with the recommendations in the Guide for the Care and Use of Laboratory Animals of Southern Medical University (Guangzhou, China). The study was approved by the ethics committee of Zhujiang Hospital, Southern Medical University. All surgical procedures and methods of euthanasia were conducted to minimize suffering.

\section{Consent for publication}

Not applicable.

\section{Competing interests}

The authors declare that they have no competing interests.

\section{References}

1. Finlay E: Review: Most interventions for preventing bone disease in chronic renal failure improved biochemical outcomes. Arch Dis Child Educ Pract Ed 97: 40, 2012.

2. Takase H, Nakazawa A, Yamashita S, Toriyama T, Sato K, Ueda R and Dohi Y: Pioglitazone produces rapid and persistent reduction of vascular inflammation in patients with hypertension and type 2 diabetes mellitus who are receiving angiotensin II receptor blockers. Metabolism 56: 559-564, 2007.

3. Varughese GI and Lip GY: Hypertension in patients with type-II diabetes: Relation to urinary albumin excretion, endothelial function and inflammation. J Hum Hypertens 19: 421-424, 2005.

4. Yamamoto S, Okada Y, Mori H, Nishida K, Uriu K and Tanaka Y: Type 2 diabetes mellitus complicated by hypertension in Japanese patients: Switching treatment from high-dose angiotensin II receptor blockers to losartan plus hydrochlorothiazide. Intern Med 53: 1283-1289, 2014.

5. Kalaitzidis R and Bakris G: Management of hypertension in patients with diabetes: The place of angiotensin-II receptor blockers. Diabetes Obes Metab 11: 757-769, 2009. 
6. Hasvold LP, Bodegård J, Thuresson M, Stålhammar J,Hammar N, Sundström J, Russell D and Kjeldsen SE: Diabetes and CVD risk during angiotensin-converting enzyme inhibitor or angiotensin II receptor blocker treatment in hypertension: A study of 15,990 patients. J Hum Hypertens 28: 663-669, 2014.

7. Daimon M, Kamba A, Murakami H, Takahashi K, Otaka H, Makita K, Yanagimachi M, Terui K, Kageyama K, Nigawara T, et al: Association between pituitary-adrenal axis dominance over the renin-angiotensin-aldosterone system and hypertension. J Clin Endocrinol Metab 101: 889-897, 2016.

8. Ficek J, Malyszko J and Chudek J: Renalase and its role in the development of hypertension in patients with chronic renal failure. Przegl Lek 72: 306-308, 2015 (In Chinese).

9. Kasacka I: Review article-involvement of gastric APUD cells in chronic renal failure. Acta Histochem 105: 319-327, 2003.

10. Bos-Touwen I, Schuurmans M, Monninkhof EM, Korpershoek Y Spruit-Bentvelzen L, Ertugrul-van der Graaf I, de Wit N and Trappenburg J: Patient and disease characteristics associated with activation for self-management in patients with diabetes, chronic obstructive pulmonary disease, chronic heart failure and chronic renal disease: A cross-sectional survey study. PLoS One 10: e0126400, 2015.

11. Nair PA, Jivani NB and Diwan NG: Kyrle's disease in a patient of diabetes mellitus and chronic renal failure on dialysis. J Family Med Prim Care 4: 284-286, 2015.

12. Guntani A, Yamaoka T, Okadome J, Kawakubo E, Kyuragi R, Homma K, Iwasa K, Matsumoto T, Okazaki J and Maehara Y: Evaluation of the paramalleolar bypass for critical limb ischemia patients on hemodialysis with diabetes mellitus and chronic renal failure. Ann Vasc Dis 6: 596-600, 2013.

13. Guerra-Martin MD, Amador-Marin B and Martinez-Montil JM: Health problems of family caregivers of people over 65 suffering from chronic renal failure: A systematic review. An Sist Sanit Navar 38: 425-438, 2015 (In Chinese).

14. Ramezani A, Nägga K, Hansson O, Lönn J, Sjöwall J, Katoozian F, Mansouri S and Nayeri F: Hepatocyte growth factor in cerebrospinal fluid differentiates community-acquired or nosocomial septic meningitis from other causes of pleocytosis. Fluids Barriers CNS 12: 22, 2015

15. Faletto DL, Kaplan DR, Halverson DO, Rosen EM and Vande Woude GF: Signal transduction in c-met mediated motogenesis. EXS 65: 107-130, 1993

16. Baum E, Pawlaczyk K, Maćkowiak B, Sosinska P, Matecka M, Kolodziejczak B, Musielak M and Breborowicz A: Levels of hepatocyte growth factor in serum correlate with quality of life in hemodialysis patients. Int J Clin Exp Pathol 8: 13477-13482, 2015.

17. Mizuno S and Nakamura T: Molecular basis for HGF-mediated regression of renal fibrosis. Nihon Rinsho 64 (Suppl 2): S312-S321, 2006 (In Chinese)

18. Zhang SH, Wen KM, Wu W, Li WY and Zhao JN: Efficacy of HGF carried by ultrasound microbubble-cationic nano-liposomes complex for treating hepatic fibrosis in a bile duct ligation rat model, and its relationship with the diffusion-weighted MRI parameters. Clin Res Hepatol Gastroenterol 37: 602-607, 2013.

19. Hasmim M, Bruno S, Azzi S, Gallerne C, Michel JG, Chiabotto G Lecoz V, Romei C, Spaggiari GM, Pezzolo A, et al: Isolation and characterization of renal cancer stem cells from patient-derived xenografts. Oncotarget 7: 15507-15524, 2016.

20. Friedewald WT, Levy RI and Fredrickson DS: Estimation of the concentration of low-density lipoprotein cholesterol in plasma, without use of the preparative ultracentrifuge. Clin Chem 18 499-502, 1972

21. Livak KJ and Schmittgen TD: Analysis of relative gene expression data using real-time quantitative PCR and the 2(-Delta Delta C(T)) method. Methods 25: 402-408, 2001

22. Li M, Shi X, Chen F and Hao F: Daphnetin inhibits inflammation in the NZB/W F1 systemic lupus erythematosus murine model via inhibition of NF- $\kappa$ B activity. Exp Ther Med 13: 455-460, 2017.
23. Naganuma Y, Ichii O, Otsuka S, Hashimoto Y and Kon Y: Analysis of TdT-mediated dUTP nick end labeling (TUNEL)-positive cells associated with cardiac myogenesis in mouse embryo. J Vet Med Sci 75: 283-290, 2013.

24. Mallavia B, Recio C, Oguiza A, Ortiz-Muñoz G, Lazaro I, Lopez-Parra V, Lopez-Franco O, Schindler S, Depping R, Egido J and Gomez-Guerrero C: Peptide inhibitor of NF- $\mathrm{NB}$ translocation ameliorates experimental atherosclerosis. Am J Pathol 182: 1910-1921, 2013.

25. Akyüz A, Yıldız A, Akıl MA, Bilik MZ, İnci Ü, Kayan F, Yıldız İ, Y1lmaz Z, Y1ldırım Y and Ülgen MS: Assessment of right ventricular systolic function in patients with chronic renal failure before and after hemodialysis by means of various echocardiographic modalities. Turk Kardiyol Dern Ars 42: 717-725, 2014 (In Chinese)

26. Ma HB, Wang R, Yu KZ and Yu C: Dynamic changes of early-stage aortic lipid deposition in chronic renal failure rats and effects of decorin gene therapy. Exp Ther Med 9: 591-597, 2015.

27. Vahedi M, Malekzadeh H, Haybar H, Soltanian AR, Abdollahzadeh S, Yoosefi H, Seyedian M, Yazdanpanah L, Saeid A, Shabanpour Fooladi M and Ghasemi M: The relationship between salivary beta-2 microglobulin and uremia intensity in men with chronic renal failure. Cell J 14: 276-281, 2013.

28. Silverberg D, Yalon T, Rimon U, Reinitz ER, Yakubovitch D, Schneiderman J and Halak M: Endovascular treatment of lower extremity ischemia in chronic renal failure patients on dialysis: Early and intermediate term results. Isr Med Assoc J 15: 734-738, 2013.

29. Berry PA and Thomson SJ: Comment on O'Brien et al: Prevalence and outcome of cirrhosis patients admitted to UK intensive care: A comparison against dialysis-dependent chronic renal failure patients. Intensive Care Med 38: 1729; author reply $1730,2012$.

30. Marcondes JA, Martins TC, Amaral AS and Nery M: Falsely elevated testosterone in a type 1 diabetes patients with acne and chronic renal failure on dialysis. Arq Bras Endocrinol Metabol 56: 319-323, 2012 (In Chinese).

31. Finegood DT: Obesity, inflammation and type II diabetes. Int J Obes Relat Metab Disord 27 (Suppl 3): S4-S5, 2003.

32. Temelkova-Kurktschiev T, Henkel E, Koehler C, Karrei K and Hanefeld M: Subclinical inflammation in newly detected Type II diabetes and impaired glucose tolerance. Diabetologia 45: 151, 2002.

33. Bitar MS, Ayed AK, Abdel-Halim SM, Isenovic ER and Al-Mulla F: Inflammation and apoptosis in aortic tissues of aged type II diabetes: Amelioration with alpha-lipoic acid through phosphatidylinositol 3-kinase/Akt- dependent mechanism. Life Sci 86: 844-853, 2010.

34. Mariappan N, Elks CM, Sriramula S, Guggilam A, Liu Z, Borkhsenious $\mathrm{O}$ and Francis J: NF-kappaB-induced oxidative stress contributes to mitochondrial and cardiac dysfunction in type II diabetes. Cardiovasc Res 85: 473-483, 2010.

35. Shaarawy M, Fathy SA, Mehany NL and Hindy OW: Circulating levels of osteoprotegerin and receptor activator of NF-kappaB ligand in patients with chronic renal failure. Clin Chem Lab Med 45: 1498-1503, 2007.

36. Shalini B and Sharma JD: Beneficial effects of emblica officinalis on fluoride-induced toxicity on brain biochemical indexes and learning-memory in rats. Toxicol Int 22: 35-39, 2015.

37. Cizmeci D and Arkun Y: Regulatory networks and complex interactions between the insulin and angiotensin II signalling systems: Models and implications for hypertension and diabetes. PLoS One 8: e83640, 2013 